\title{
Review \\ Contacts for Molybdenum Disulfide: Interface Chemistry and Thermal Stability
}

\author{
Keren M. Freedy and Stephen J. McDonnell * \\ Department of Materials Science and Engineering, University of Virginia, Charlottesville, VA 22904, USA; \\ kmfreedy@gmail.com \\ * Correspondence: mcdonnell@virginia.edu
}

Received: 7 January 2020; Accepted: 31 January 2020; Published: 4 February 2020

\begin{abstract}
In this review on contacts with $\mathrm{MoS}_{2}$, we consider reports on both interface chemistry and device characteristics. We show that there is considerable disagreement between reported properties, at least some of which may be explained by variability in the properties of geological $\mathrm{MoS}_{2}$. Furthermore, we highlight that while early experiments using photoemission to study the interface behavior of metal- $\mathrm{MoS}_{2}$ showed a lack of Fermi-level pinning, device measurements repeatedly confirm that the interface is indeed pinned. Here we suggest that a parallel conduction mechanism enabled by metallic defects in the $\mathrm{MoS}_{2}$ materials may explain both results. We note that processing conditions during metal depositions on $\mathrm{MoS}_{2}$ can play a critical role in the interface chemistry, with differences between high vacuum and ultra-high vacuum being particularly important for low work function metals. This can be used to engineer the interfaces by using thin metal-oxide interlayers to protect the $\mathrm{MoS}_{2}$ from reactions with the metals. We also report on the changes in the interfaces that can occur at high temperature which include enhanced reactions between Ti or $\mathrm{Cr}$ and $\mathrm{MoS}_{2}$, diffusion of $\mathrm{Ag}$ into $\mathrm{MoS}_{2}$, and delamination of Fe. What is clear is that there is a dearth of experimental work that investigates both the interface chemistry and device properties in parallel.
\end{abstract}

Keywords: transition metal dichalcogenides; semiconductors; nanoelectronics; contacts; interface chemistry; contact resistance; thermal boundary conductance; X-ray photoelectron spectroscopy

\section{Introduction}

The last 15 years have seen a renewed interest in van der Waals solids with a new focus on their potential in nanoelectronic applications. These materials have a long history of use as dry lubricants [1] and have been previously studied for their photoelectrochemical [2-4] and photovoltaic [5] properties. While there have been prior reports on monolayer 2D materials including 'a single carbon hexagonal layer' [6] and 'single-layer $\operatorname{MoS}_{2}$ ' [7], it was the seminal work of Novoselov and Geim [8,9] that triggered this remarkable interest in monolayer 2D for nanoelectronics. Since the isolation of monolayer graphene and the demonstration of its electronic properties [8-10], the interest in 2D materials beyond graphene has also been increasing. These 2D materials beyond graphene include hexagonal boron nitride (hBN), transition metal dichalcogenides, Silicene/Germanene/Stanene, as well as group III and group IV metal chalcogenides such as GaSe or $\mathrm{SnS}_{2}$ [11-13]. Similarly, despite monolayer $\mathrm{MoS}_{2}$ being exfoliated as early as 1986 [7], it was the demonstration of a monolayer $\mathrm{MoS}_{2}$ based transistor [14] that sparked an exponential rise in publications on the properties, synthesis, and electronic device applications of $\mathrm{MoS}_{2}$ [15]. A fundamental component of any electronic device is the metal contact that controls the flow of current and heat to external circuitry. This review article will cover the interface chemistry and properties of metal contacts to semiconducting 2D materials, with a primary focus on the metal- $\mathrm{MoS}_{2}$ interface. The role of processing conditions will also be discussed. Table 1 captures a summary of some of the metal- $\mathrm{MoS}_{2}$ research that has been carried out. It becomes clear that while 
there are many interface chemistry studies as well as studies focused on device properties, there is a lack of correlation studies that concurrently investigate chemistry, device properties and effects of processing. 
Table 1. Summary of literature on experimental chemical and electronic characterization of metal-MoS 2 interfaces.

\begin{tabular}{|c|c|c|c|c|c|}
\hline & Ref. & Deposition & Annealing & Characterization & Key Result \\
\hline \multirow[t]{5}{*}{ Ti } & {$[16]$} & UHV & None & XPS & Reaction of $\mathrm{Ti}+\mathrm{MoS}_{2} \rightarrow \mathrm{Ti}-\mathrm{S}+\mathrm{Mo}^{0}$ at room temperature \\
\hline & [17] & UHV & None & TEM, EELS & Reaction of $\mathrm{Ti}+\mathrm{MoS}_{2} \rightarrow \mathrm{Ti}-\mathrm{S}+\mathrm{Mo}^{0}$ at room temperature \\
\hline & [18] & HV and UHV & None & XPS & Reaction occurs in UHV only and not in HV deposition \\
\hline & [19] & UHV & In total, $300^{\circ} \mathrm{C}$ for $2 \mathrm{~h}$ in $\mathrm{HV}$ & TLM & High RC $(\sim 7-9 \mathrm{k} \Omega \mu \mathrm{m})$ \\
\hline & [20] & Unreported & None & FET I-V Curves & EF pinned near $\mathrm{MoS}_{2}$ conduction band $(\Phi=0.050 \mathrm{eV})$ \\
\hline \multirow[t]{3}{*}{$\mathbf{N i}$} & $\begin{array}{l}{[21,22]} \\
{[22]}\end{array}$ & UHV & $\begin{array}{l}\text { Heated sequentially in UHV } \\
\text { to } 927^{\circ} \mathrm{C} \text {; time not specified }\end{array}$ & $\begin{array}{l}\text { Auger electron } \\
\text { spectroscopy (AES) }\end{array}$ & $\begin{array}{l}\text { - No interactions below } 327^{\circ} \mathrm{C} \\
\text { - Some diffusion of Ni into } \mathrm{MoS}_{2} \text { at } 327-527^{\circ} \mathrm{C} \\
\text { - Agglomeration of Ni film }>527^{\circ} \mathrm{C}\end{array}$ \\
\hline & [19] & $\mathrm{HV}$ & In total, $300^{\circ} \mathrm{C}$ for $2 \mathrm{~h}$ in $\mathrm{HV}$ & TLM & $\mathrm{RC} \sim 4-7 \mathrm{k} \Omega \mu \mathrm{m}$ \\
\hline & [20] & Unreported & None & FET I-V Curves & n-type Fermi-level pinning $(\Phi=0.150 \mathrm{eV})$ \\
\hline \multirow[t]{4}{*}{$\mathrm{Au}$} & [23] & UHV & None & XPS & No chemical bonding \\
\hline & [24] & HV and UHV & None & XPS & No chemical bonding \\
\hline & [19] & $\mathrm{HV}$ and $\mathrm{UHV}$ & In total, $300^{\circ} \mathrm{C}$ for $2 \mathrm{~h}$ in $\mathrm{HV}$ & $\begin{array}{l}\text { TLM } \\
\text { FET- IV curves }\end{array}$ & $\begin{array}{l}\text { - RC for } \mathrm{Au} \sim 0.7-2 \mathrm{k} \Omega \mu \mathrm{m} \text { in } \mathrm{UHV} ; \sim 3.5-5 \mathrm{k} \Omega \mu \mathrm{m} \text { in } \mathrm{HV} \\
-\Phi=0.15 \mathrm{eV}\end{array}$ \\
\hline & [25] & Unreported & Unreported & $\begin{array}{l}\text { TLM } \\
\text { FET I-V Curves }\end{array}$ & $\begin{array}{l}-\mathrm{RC} \sim 30-45 \Omega \mathrm{mm} \\
-\Phi=0.12 \mathrm{eV}\end{array}$ \\
\hline \multirow[t]{2}{*}{$\mathrm{Cr}$} & {$[26,27]$} & UHV & $\begin{array}{l}\text { Heated sequentially in UHV } \\
\text { from } 425-850{ }^{\circ} \mathrm{C} \text {, } \\
\text { Time not specified }\end{array}$ & XPS & $\begin{array}{l}\text { - Reaction of } \mathrm{Cr}+\mathrm{MoS}_{2} \rightarrow \mathrm{Cr}-\mathrm{S}+\mathrm{Mo}^{0} \text { at room temperature } \\
\text { - Reaction driven to completion }<425^{\circ} \mathrm{C} \\
\text { - Increase in } \mathrm{S} \text { composition at the } \mathrm{Cr} \text { surface with temp. } \\
\text { - Coalescence of } \mathrm{Cr}>650{ }^{\circ} \mathrm{C}\end{array}$ \\
\hline & [24] & HV and UHV & None & XPS & $\begin{array}{l}\text { - Reaction occurs under both } \mathrm{HV} \text { and } \mathrm{UHV} \text { conditions } \\
\text { - Both depositions result in } \mathrm{Mo}^{0} \text { and } \mathrm{Cr}_{\mathrm{x}} \mathrm{S}_{\mathrm{y}} \\
\text { - HV deposition conductions also result in } \mathrm{Cr}_{\mathrm{x}} \mathrm{O}_{\mathrm{y}}\end{array}$ \\
\hline
\end{tabular}


Table 1. Cont.

\begin{tabular}{|c|c|c|c|c|c|}
\hline & Ref. & Deposition & Annealing & Characterization & Key Result \\
\hline \multirow[t]{2}{*}{ Mn } & [28] & HV & None & XPS & Chemical reaction observed \\
\hline & [29] & $\mathrm{HV}$ and UHV & $\begin{array}{l}\text { Heated sequentially in UHV } \\
\text { from } 497 \text { to } 857^{\circ} \mathrm{C} \text {, } \\
\text { time not specified }\end{array}$ & XPS & $\begin{array}{l}\text { - Reaction of } \mathrm{Mn}+\mathrm{MoS}_{2} \rightarrow \mathrm{Mn}-\mathrm{S}+\mathrm{Mo}^{0} \text { as deposited } \\
\text { - Reaction driven to completion above } 497^{\circ} \mathrm{C} \\
\text { - Increase in } \mathrm{S} \text { composition at the Mn surface with temp. } \\
\text { - Coalescence of } \mathrm{Mn}>767^{\circ} \mathrm{C}\end{array}$ \\
\hline \multirow[t]{2}{*}{$\mathrm{Fe}$} & {$[30]$} & UHV & $\begin{array}{l}\text { Heated sequentially in UHV } \\
\text { from } 327 \text { to } 927^{\circ} \mathrm{C} \text {, time not } \\
\text { specified }\end{array}$ & XPS & $\begin{array}{l}\text { - No evidence of reaction in the bulk } \\
\text { - Fe-S surface states and S-vacancy states are observed following initia } \\
\text { deposition } \\
\text { - Heating eliminates these chemical states }\end{array}$ \\
\hline & {$[31]$} & UHV & $\begin{array}{l}\mathrm{UHV} \text { at } 927^{\circ} \mathrm{C} \text { for a few } \\
\text { minutes; repeated } 20 \text { times }\end{array}$ & $\begin{array}{l}\text { AES with } \mathrm{Ar}^{+} \text {depth } \\
\text { profiling }\end{array}$ & $\begin{array}{l}\text { - Intercalation of Fe between } \mathrm{MoS}_{2} \text { layers due to annealing } \\
\text { - Potential formation of } \mathrm{FeMo}_{2} \mathrm{~S}_{4}\end{array}$ \\
\hline \multirow[t]{5}{*}{$\mathbf{P d}$} & {$[28]$} & HV & None & XPS & No chemical bonding \\
\hline & [23] & UHV & None & XPS & No chemical bonding \\
\hline & {$[32]$} & UHV & None & XPS & $\begin{array}{l}\text { - No chemical bonding } \\
\text { - Perturbation of the } \mathrm{MoS}_{2} \text { surface due to Pd overlayer } \\
\text { - Pd aligns midgap with } \mathrm{MoS}_{2}(\Phi=0.67 \mathrm{eV})\end{array}$ \\
\hline & [25] & Unreported & Unreported & $\begin{array}{l}\text { TLM } \\
\text { FET I-V Curves }\end{array}$ & $\begin{array}{l}-\mathrm{RC} \sim 75-200 \mathrm{k} \Omega \mathrm{mm} \\
-\Phi=0.4 \mathrm{eV}\end{array}$ \\
\hline & {$[31]$} & UHV & $\begin{array}{l}\text { UHV at } 927^{\circ} \mathrm{C} \text { for a few } \\
\text { minutes; repeated } 20 \text { times }\end{array}$ & $\begin{array}{l}\text { AES with } \mathrm{Ar}^{+} \text {depth } \\
\text { profiling }\end{array}$ & $\begin{array}{l}\text {-Diffusion of Pd into } \mathrm{MoS}_{2} \text { layers due to annealing; uniformly } \\
\text { distributed in the bulk unlike Fe }\end{array}$ \\
\hline \multirow[t]{3}{*}{ Al } & {$[28]$} & $\mathrm{HV}$ & None & XPS & No chemical bonding \\
\hline & [16] & UHV & None & XPS & No chemical bonding \\
\hline & [33] & Unreported & In total, $110^{\circ} \mathrm{C}$ for $15 \mathrm{~h}$ in $\mathrm{HV}$ & FET I-V Curves & Significant electron doping manifested in no OFF state \\
\hline In & [28] & HV & None & XPS & No chemical bonding \\
\hline Mg & [16] & UHV & None & XPS & Evidence of chemical bonding \\
\hline Mo & [34] & Unreported & In total, $146^{\circ} \mathrm{C}$ for $2 \mathrm{~h}$ & FET I-V Curves & $-\mathrm{RC} \sim 2 \mathrm{k} \Omega \mu \mathrm{m}$ \\
\hline
\end{tabular}


Table 1. Cont

\begin{tabular}{|c|c|c|c|c|c|}
\hline & Ref. & Deposition & Annealing & Characterization & Key Result \\
\hline \multirow[t]{4}{*}{ Ag } & [35] & $\mathrm{HV}$ & $\begin{array}{l}\text { In total, } 150^{\circ} \mathrm{C} \text { for } 24 \mathrm{~h} \text { in } \mathrm{HV} \\
\text { followed by RTA in Ar at } \\
200-500^{\circ} \mathrm{C}\end{array}$ & $\begin{array}{l}\text { TLM } \\
\text { FET I-V Curves }\end{array}$ & $\begin{array}{l}\text { - Negligible reduction in } \mathrm{RC} \text { after } 24 \mathrm{~h} \mathrm{HV} \text { anneal at } 150^{\circ} \mathrm{C} \\
\text { - RC reduced from } \sim 2 \mathrm{k} \Omega \mu \mathrm{m} \text { to } 0.2-0.7 \mathrm{k} \Omega \mu \mathrm{m} \text { after annealing in RTA } \\
\text { at } 200-500{ }^{\circ} \mathrm{C} \\
\text { - Reduction in } \mathrm{RC} \text { is attributed to diffusion of } \mathrm{Ag} \text { resulting in doping }\end{array}$ \\
\hline & [36] & Unreported & None & FET I-V Curves & - 60x larger ON current than Ti contacted devices \\
\hline & [37] & Unreported & In total, $400-600{ }^{\circ} \mathrm{C}$ for $5 \mathrm{~min}$ & Radioactive tracer & $\begin{array}{l}\text { Diffusion of } \mathrm{Ag} \text { into } \mathrm{MoS}_{2} \text { crystal results in intercalation between } \\
\text { layers; no diffusion detected in-plane }\end{array}$ \\
\hline & [38] & UHV & $\begin{array}{l}\text { In total, }-173 \text { to } 577^{\circ} \mathrm{C} \text { in } \\
\mathrm{UHV} \text {, time not specified }\end{array}$ & XPS and AES & $\begin{array}{l}\text { - No reaction from }-173 \text { to } 27^{\circ} \mathrm{C} \\
\text { - Diffusion of Ag into bulk after annealing to } 326^{\circ} \mathrm{C} \text {; negative binding } \\
\text { energy shift due to silver } \rightarrow \text { sulfide charge transfer } \\
\text { - Heating above } 526^{\circ} \mathrm{C} \text { restored binding energies to pre-anneal } \\
\text { positions likely due to the diffusion of Ag into } \mathrm{MoS}_{\mathrm{x}} \text { or the formation } \\
\text { of AgMoS } \text {. } \\
\text { - Ag clusters form on surface after annealing to } 577^{\circ} \mathrm{C}\end{array}$ \\
\hline \multirow[t]{2}{*}{ Sc } & [20] & Unreported & None & FET I-V Curves & EF pinned near $\mathrm{MoS}_{2}$ conduction band $(\Phi=0.030 \mathrm{eV})$ \\
\hline & [24] & HV and UHV & None & XPS & $\begin{array}{l}\text { - Reaction occurs under both } \mathrm{HV} \text { and } \mathrm{UHV} \text { conditions } \\
\text { - } \mathrm{HV} \text { deposition results in } \mathrm{MoO}_{\mathrm{x}}, \mathrm{MoO}_{\mathrm{x}} \mathrm{S}_{\mathrm{y}} \text {, and } \mathrm{Sc}_{\mathrm{x}} \mathrm{O}_{\mathrm{y}} \\
\text { - UHV deposition results in } \mathrm{Mo}^{0} \text { and } \mathrm{ScS}_{\mathrm{x}} \text { and }\end{array}$ \\
\hline $\mathbf{P t}$ & [20] & Unreported & None & FET I-V Curves & n-type Fermi-level pinning $(\Phi=0.230 \mathrm{eV})$ \\
\hline Ir & [24] & HV and UHV & None & XPS & $\begin{array}{l}\text { - Reaction occurs under both } \mathrm{HV} \text { and UHV conditions } \\
\text { - Both depositions result in } \mathrm{MoS}_{x} \text { and } \mathrm{IrS}_{x} \\
\text { - HV deposition also results in } \mathrm{IrO}_{x}\end{array}$ \\
\hline
\end{tabular}




\section{Transition Metal Dichalcogenides}

$\mathrm{MoS}_{2}$ is the most commonly studied member of the transition metal dichalcogenide (TMDC) family of layered materials. Layered materials are defined as solid materials that are held together in part by secondary bonding such as van der Waals forces. By data mining the Materials Project Database, more than 1000 'weakly bonded' materials have been identified [39]. These included both layered materials and also one-dimensional chains. The TMDC family takes the form of $\mathrm{MX}_{2}$ where $\mathrm{M}$ is a transition metal and $\mathrm{X}$ is a chalcogen ( $\mathrm{S}, \mathrm{Se}$, or Te). This is illustrated in Figure 1. Unlike graphene, which is a flat layer of carbon with all covalent bonds existing on a 2D plane, a single 'layer' of a TMDC is actually three atomic layers thick and consist of an X-M-X. This layer is then held to other layers via van der Waals forces. In the case of $\mathrm{MoS}_{2}$, there exist three polytypes that are shown in Figure 1. The $1 \mathrm{~T}$ and also the distorted $1 \mathrm{~T}^{\prime}$ phase are metallic and of particular interest for catalysis [40-42] and also low resistance contacts [43]. The semiconducting $3 \mathrm{R}$ polytype can be generated through process control and has recently be shown to have comparable performance to $1 \mathrm{~T}$ with respect to hydrogen evolution reactions [44]. However, it is the $2 \mathrm{H}$ phase that is thermodynamically stable and is therefore the most common polytype studied.

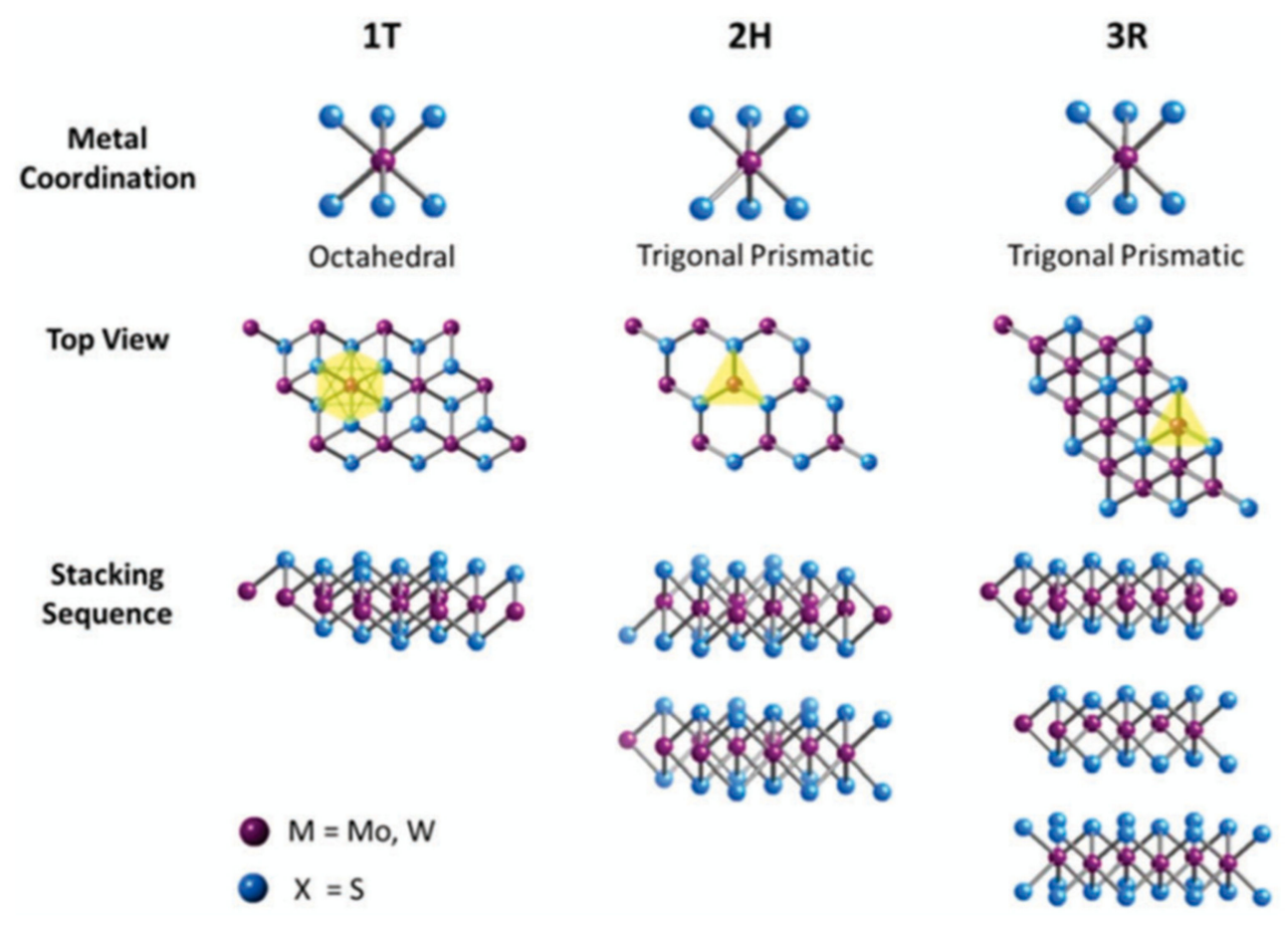

Figure 1. Metal coordination and stacking sequences of transition metal dichalcogenide (TMDC) structural unit cells. Metal coordination can be either octahedral or trigonal prismatic. The octahedral coordination allows stacking sequences which yield a tetragonal symmetry (1T). Dissimilar stacking sequences of trigonal prismatic single layers can give rise to different symmetries: hexagonal symmetry $(2 \mathrm{H})$ and rhombohedral symmetry (3R). Reproduced from R.J. Toh et al. Chem Commun., 2017, 53, 3054 - Published by The Royal Society of Chemistry.

The TMDC family of materials exhibits a range of electronic properties including semiconductivity, semimetallic behavior, and superconductivity. They have a long history and many aspects have been covered in other reviews. A detailed review of their structure and properties was carried out in 1969 [1]. More recent reviews include those focused on combinations of synthesis, applications, and functionalization $[15,45-53]$. This review will focus specifically on the metal-TMDC interface chemistry and thermal stability. 


\section{Contacts for Nanoelectronics}

Much of the recent focus on the metal-TMDC interfaces has been largely motivated by the goal of achieving Ohmic or low resistance contacts for electronic devices. A conventional approach to low resistance contacts stems from the Schottky Mott model, which predicts that the height of the barrier for electron injection is dependent on the degree of band bending at the metal/semiconductor interface [23,54]. This is quantified by the absolute value of the difference between the work function of the metal and the electron affinity of the semiconductor [55]. For an n-type semiconductor, the condition for an Ohmic contact is that the work function of the metal align in the conduction band of the semiconductor [56]. This condition results in no barrier to electron flow into the semiconductor. In practice Ohmic contacts are often achieved by satisfying the condition that the work function of the metal be less than that of the semiconductor to ensure a small barrier, and then complementing this by highly doping the contact area so that any barrier is sufficiently thin to allow easy tunneling. In fact, this approach was adapted and demonstrated for 2D materials by Chuang et al. [57]. The authors doped their TMDC layers $\left(\mathrm{WSe}_{2}, \mathrm{MoS}_{2}\right.$, and $\mathrm{MoSe}_{2}$ ) with $\sim 0.5 \% \mathrm{Nb}$. $\mathrm{NbSe}_{2}$ and $\mathrm{NbS}_{2}$ are metallic and so the effect was similar to degenerately doping the region under the contact. Based on the Schottky Mott model, metal contacts should be chosen based on work function to meet the condition for Ohmic contact. Given the propensity of $\mathrm{MoS}_{2}$ for n-type doping [58], the ideal candidate based on this model would therefore be low work function metal. The converse is true for $\mathrm{WSe}_{2}$ which is more likely to exhibit p-type doping [59] making high work function metals preferable for forming Ohmic contacts. Low work function metals including Ti (4.3 eV) [20,60], In (4.1 eV) [61], Mo (4.5 eV) [34], Cr (4.5 eV) [60], and Sc $(3.5 \mathrm{eV})$ [20] may seem to be favorable candidates for $\mathrm{MoS}_{2}[48,61]$ High work function metals include $\mathrm{Ni}(5.0 \mathrm{eV})$ [20], Pt (5.9-6.1 eV) [20,62], Au (5.4-5.7 eV) [20,62], Pd (5.6 eV) [61].

It has been experimentally observed that metal- $\mathrm{MoS}_{2}$ interfaces rarely adhere to the behavior predicted by the Schottky Mott model $[19,20,60,62,63]$ Contact behavior (Ohmic vs. Schottky or n-type vs. p-type) is found to be not entirely dependent on the work function difference between the semiconductor and the metal. For example, in the first report of a $\mathrm{MoS}_{2}$-based transistor, Radisavljevic et al. [64] report Ohmic behavior for Au contacts to n-type $\mathrm{MoS}_{2}$. Given the high work function of Au, this result is surprising. Similarly, Das et al. [20] investigated Sc, Ti, Ni and Pt contacts on $\mathrm{MoS}_{2}$ and showed that, despite markedly different metal work functions, all appear to be Fermi-level pinned to just below the conduction band. While, Kaushik et al. [25] observe the same n-type behavior for devices contacted with $\mathrm{Au}$ and Pd, Fontana et al. [65] show that Pd can form a p-type contact in agreement with Schottky Mott model, whereas Au forms an n-type contact in agreement with the results of others.

It is apparent that two types of discrepancies exist in the literature concerning the electronic properties of metal-TMDC contacts. The first, as stated previously, is the deviation of experimental results from the Schottky Mott model. The model assumes that the two materials maintain their intrinsic properties upon contact. Given the absence of dangling bonds on the surface of TMDCs, they were believed to be chemically inert exhibiting minimal interactions with a metal overlayer [28]. This is in contrast with conventional semiconductors, like Si or group III-V materials such GaAs, which have surface dangling bonds that result in the formation of defect-induced or metal-induced gap states that pin the Fermi level $[65,66]$ Gong et al. [62] suggest that in metal-MoS ${ }_{2}$ contacts, dipoles formed at the interface modify the metal work function, and that the S-Mo bonding is weakened by the adsorbed metal leading to the formation of states in the band gap of $\mathrm{MoS}_{2}$. McDonnell et al. [23] show that the presence of defects in geological $\mathrm{MoS}_{2}$, specifically Mo-rich clusters, are a likely explanation for the effective lowering of the Schottky barrier height in $\mathrm{MoS}_{2}$. These defects provide parallel conduction paths for the electrons. One would be the direct path from metal to $\mathrm{MoS}_{2}$ and the other would be metal-defect-MoS . If the defect offers a low Schottky barrier, then even small areal densities of defects (on the order of $1 \%$ ) will dominate the current-voltage characteristics of a contact due to the exponential dependence on barrier height as shown in Figure 2 . This can manifest in the measurement of low electron Schottky barrier contacts even with high work function metals such as $\mathrm{Au}$ or Pt. The authors showed that even $0.3 \%$ surface coverage of 
defects was sufficient to explain the experimental observation of anomalously high reverse bias currents. Furthermore, Figure 2c demonstrates that local variations in defect concentration could have a significant impact on device-to-device variability. Additionally, a number of low work function metals including Ti, Mn, Ir, Sc, and Cr have been found to react with TMDCs $[16,18,24,27,29,67]$. Reaction products can also result in the creation of states in the TMDC band gap which pin the Fermi level [67]. Ultimately, the deviation from the Schottky Mott model is the result of different chemical and electronic interactions that occur at the metal/TMDC interface.

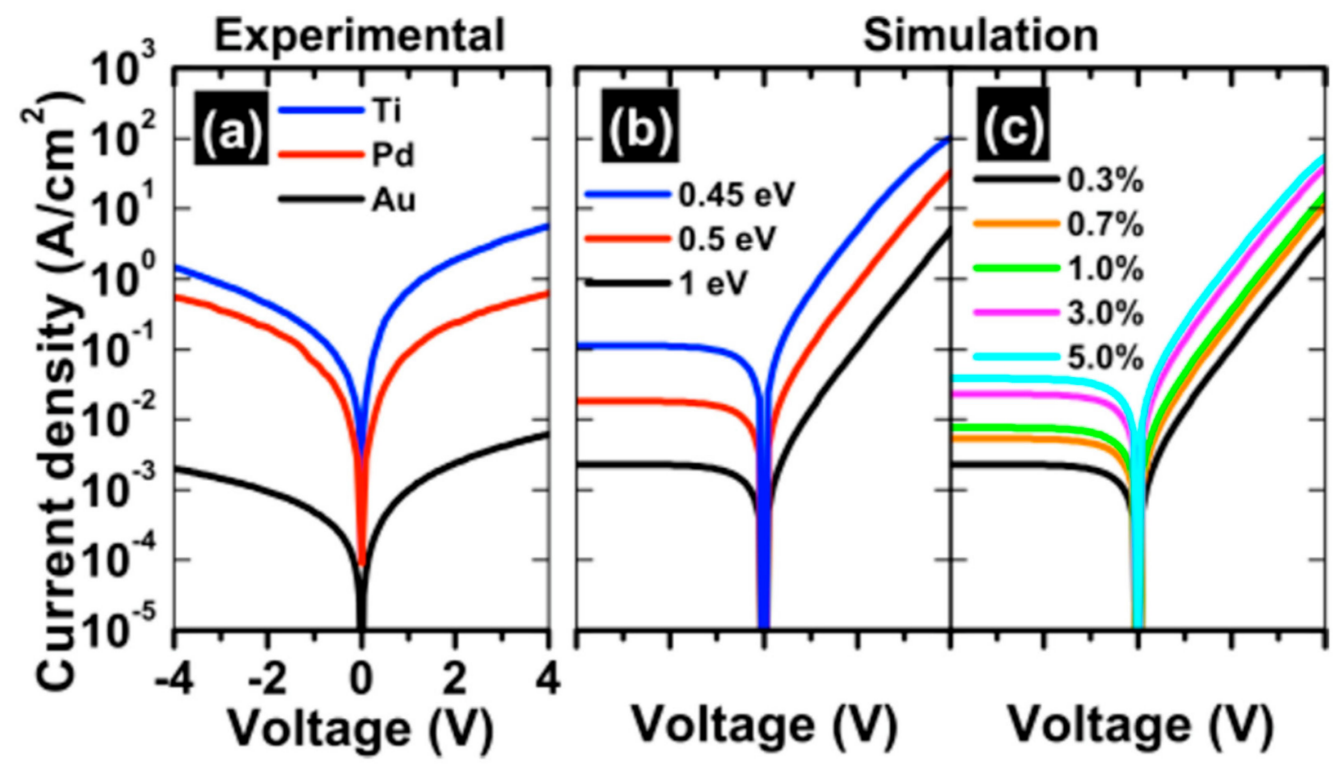

Figure 2. Comparison of the experimental and simulated IV characteristics. (a) Experimental current-voltage characteristics of Ti-MoS, $\mathrm{Pd}-\mathrm{MoS}_{2}$, and $\mathrm{Au}-\mathrm{MoS}_{2}$ for comparison to the simulated curves $(\mathbf{b}, \mathbf{c})$. (b) Simulated IV characteristics for an inhomogeneous interface assuming fixed defect areal density of $0.3 \%$ with metal electron Schottky barriers of $0.45,0.5$, and $1 \mathrm{eV}$. (c) Fixed metal electron Schottky barrier of $1 \mathrm{eV}$ and varying defect areal density of $0.3,0.7,1,3$, and $5 \%$. Both (b) and (c) assume the defect electron Schottky barrier to be $0.4 \mathrm{eV}$ and series resistance of $25 \Omega$. Reprinted with permission from McDonnell et al. ACS Nano 2014, 8, 3, 2880-2888. Copyright 2014 American Chemical Society.

The second discrepancy in contact behavior is that which is found between different reports in the literature studying the same metal-TMDC systems. For example McDonnell et al. reported that two $\mathrm{Au}-\mathrm{MoS}_{2}$ contacts on the same $\mathrm{MoS}_{2}$ crystal separated by only millimeters exhibited different behavior, with one suggesting p-type and the other n-type $\mathrm{MoS}_{2}$ [23]. Another example already mentioned is the n-type conduction observed by Kaushik et al. and the p-type conduction reported by Fontana et al. for Pd-MoS 2 contacts. Similarly, English et al. report that Ti contacts behave worse than Ni contacts whereas Das et al. report the opposite. We note that the key finding in the paper by English et al. is that Au contacts deposited in UHV $\left(\sim 10^{-9}\right.$ Torr $)$ exhibit contact resistance that is three times less than that of Au contacts deposited in HV ( $10^{-6}$ Torr). This illustrates that two seemingly identical metal-TMDC systems can exhibit different electronic properties due to different processing conditions, highlighting the important role of processing in interface properties that are often discussed in the literature as solely material-dependent. Processing effects also explain deviations between theory and experiment. For example, Chaung et al. show that $\mathrm{MoO}_{x}$ contacts to p-type $\mathrm{MoS}_{2}$ and p-type WSe 2 exhibit Schottky barriers [68]. McDonnell et al. note that this deviates from band alignment calculations which predict Ohmic behavior [68]. The disagreement is attributed to the deposition of $\mathrm{MoO}_{\mathrm{x}}$ in $\mathrm{HV}$, where the deposition results in a higher concentration of carbon in the film yielding a lower $\mathrm{MoO}_{\mathrm{x}}$ work function. 


\section{Interface Chemistry}

An important and potentially dominant factor in metal-semiconductor contacts is the interface chemistry. Allain et al. [63] defined two potential metal-2D interfaces in their work. In a conventional metal-semiconductor interface, there are primary bonds between the metal and the semiconductor. However, for 2D materials, it is often assumed that there will be a van der Waals gap at the contact interface due to the lack of dangling bonds. Allain et al. [63] considered that the van der Waals interface was only one type of interface and that the other would be one were primary bonds did exist. They used Ti as an example of a metal that would form bonds to 2D materials. Clearly there actually exists a spectrum of interfaces that exist between these two extremes [17,69].

A recent review by Domask et al. [70] focuses on thermodynamic predictions of transition metal-MoS ${ }_{2}$ interface reactions. The key prediction is that many metals will react with $\mathrm{MoS}_{2}$. This is important because metal reactions with $\mathrm{MoS}_{2}$ would form an interface chemistry distinctly different from van der Waals interface. This is quite consistent with early experimental reports from the 1980s. For example, Kamaratos and Papageorgopoulos investigated Fe and Ni particles on the $\mathrm{MoS}_{2}$ surface. They found that both formed islands on the surface at room temperature [22,31]. McGovern et al. [16] and later Lince et al. [28] would both report on a range of metals on $\mathrm{MoS}_{2}$, studied by photoemissions spectroscopy. McGovern considered a range of metals and reported their calculated heats of reaction $\left(\Delta H_{\mathrm{R}}\right)$ for these metals with $\mathrm{MoS}_{2}$. Their focus was on reactive metals, but they acknowledged prior evidence [71,72] that $\Delta H_{\mathrm{R}}$ values as high as $0.5 \mathrm{eV} /$ atom may still result in reactions. Therefore, they studied $\mathrm{Cu}, \mathrm{Ni}$, and In with $\Delta H_{\mathrm{R}}$ values from 0 to $0.5 \mathrm{eV} /$ atom and $\mathrm{Ti}, \mathrm{Al}$, and $\mathrm{Mg}$ with $\Delta H_{\mathrm{R}}$ values from -2.22 to $0 \mathrm{eV} /$ atom. Their results showed that $\mathrm{Cu}$ and $\mathrm{In}$ were not reactive while $\mathrm{Ti}$ and $\mathrm{Mg}$ were reactive, as predicted. However, they saw that $\mathrm{Ni}$ did show some reaction while $\mathrm{Al}$ did not. Their results regarding $\mathrm{Ni}$ will be discussed in comparison to more results later, but with respect to $\mathrm{Al}$, the authors concluded that either photoemission wasn't sufficiently sensitive to detect reactions or that there were large kinetic barriers preventing it. The results of the study suggest that calculations based on bulk thermodynamics are not entirely predictive of reactivity for metal-TMDC systems.

Lince et al. [28] focused on measuring the band bending induced by metal depositions on $\mathrm{MoS}_{2}$ surfaces, with a discussion of interface chemistry. They considered $\mathrm{Ag}, \mathrm{Al}, \mathrm{Au}, \mathrm{Co}, \mathrm{Fe}, \mathrm{In}, \mathrm{Mn}, \mathrm{Pd}$, $\mathrm{Rh}, \mathrm{Ti}$, and $\mathrm{V}$. Of these, they only saw reactions with $\mathrm{Mn}$. This is in contrast to the earlier work of McGovern which reported Ti reactions with $\mathrm{MoS}_{2}$. Lince et al. [28] drew attention to this fact and speculated that their own evaporation of Ti may have resulted in some Ti oxidation because their depositions were carried out at $3 \times 10^{-8}$ Torr, while McGovern et al. [16] used $2 \times 10^{-9}$ Torr. This may seem insignificant, however, McDonnell et al. [16] would later show large differences in Ti depositions carried out under $\sim 10^{-9}$ Torr and $\sim 10^{-7}$ Torr conditions, while Freedy et al. [73] would show that even $10^{-6}$ Torr to $10^{-7}$ Torr could yield large changes in the Ti chemistry.

With respect to Fermi-level pinning, Lince et al. [28] used the $\mathrm{MoS}_{2}$ surface to test contemporary theories on Fermi-level pinning. In particular, the authors noted that prior work had shown that the 'index of interface behavior' which is defined as the Schottky barrier divided by the electron affinity of the metal contact $\mathrm{S}^{\prime}=\left(\mathrm{d} \varphi_{\mathrm{B}} / \mathrm{d} \chi_{\mathrm{M}}\right)$, was shown to vary markedly between ionic and covalent materials [74]. For a metal-semiconductor system where the Schottky-Mott model is observed, the Schottky barrier would be linearly dependent on the metal work function (or electron affinity) and $\mathrm{S}^{\prime}$ should have a slope of 1 . In cases of severe Fermi-level pinning, $S^{\prime}$ would have a slope closer to 0.1. It had been shown in early work, that if one plots the $S^{\prime}$ values obtained for a range of compound semiconductors against the electronegativity difference of the elements in the compound (which would indicate the degree of ionicity) there is a dramatic shift between $S^{\prime}$ values close to 0.1 (high pinning) to $\mathrm{S}^{\prime}$ values close to 1 (little/no pinning) at $\Delta \chi$ values of $\sim 0.7 \mathrm{eV}$ as shown in Figure 3 [74]. This was deemed to be a transition between covalent and ionic character. In the work of Lince et al. [28]. the authors chose $\mathrm{MoS}_{2}$, with a $\Delta \chi$ value of only 0.42 , to test whether or not the degree of Fermi-level pinning was related primarily to the bonding type of the semiconductor (ionic or covalent), or instead to the reactivity of the substrate. Interestingly the authors found that the index of interface behavior 
was $\mathrm{S}^{\prime} 1.28 \pm 0.22 \mathrm{eV}$. The implications of this result, taken together with those of Das et al. [20] and McDonnell et al. [23] will be discussed later.

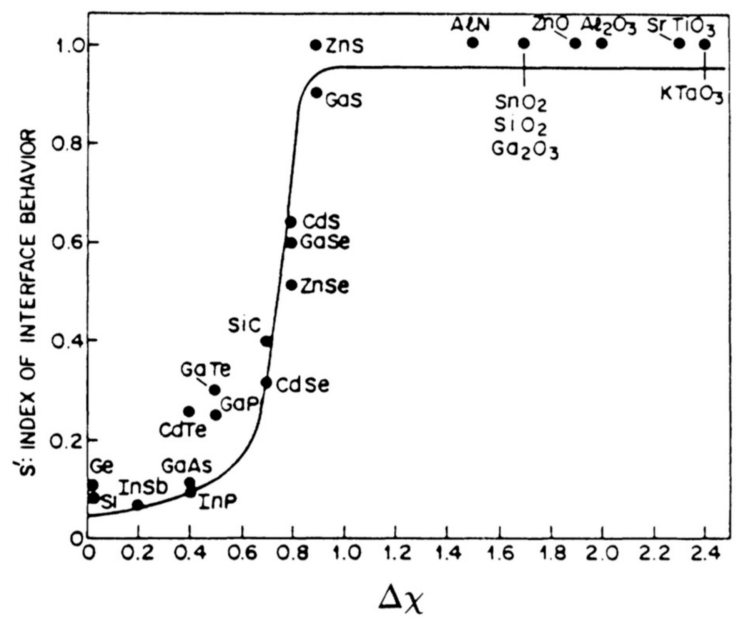

Figure 3. Collected data representing several independent experiments plotted as a function of lattice electronegativity difference $\Delta x$. Reprinted with permission from Kurtin et al, Phys Rev Lett., 22, 1433 (1969). Copyright (1969) by the American Physical Society.

Durbin et al. [26] used soft x-ray photoemission to study the reactions between $\mathrm{Cr}$ and $\mathrm{MoS}_{2}$ during ultra-high-vacuum electron beam deposition and post deposition annealing. It was found that $\mathrm{Cr}$ reacted with the $\mathrm{MoS}_{2}$ to form metallic Mo metal, $\mathrm{Cr}$ with intermixed S and a sulfur rich surface [26,27]. The same group reported similar reactions with $\mathrm{Mn}$, where MnS clearly formed in addition to metal Mo [29]. However, they also showed that, in contrast, Fe deposition resulted in only surface Fe-S phases and S-vacancy formation rather than bulk FeS formation [30]. They stated that these three elements followed the expectations of bulk thermodynamics, since the Fe reaction with $\mathrm{MoS}_{2}$ to form FeS or $\mathrm{FeS}_{2}$ yields a slightly positive $\Delta \mathrm{G}$ of +3 and $14.1 \mathrm{kcal} / \mathrm{mol}$, respectively, $\mathrm{CrS}$ would be $-10.1 \mathrm{kcal} / \mathrm{mol}$ and $\mathrm{MnS}$ would be $-25.2 \mathrm{kcal} / \mathrm{mol}$, indicated that a reaction with Fe is not expected, while reactions with $\mathrm{Cr}$ and $\mathrm{Mn}$ should occur with Mn being stronger [26].

\section{The Impact of Processing Conditions on Interface chemistry}

\subsection{Deposition Ambient}

As mentioned earlier, the only contradiction between the work of McGovern et al. [16] and Lince et al. [28] was that McGovern observed expected reactions between Ti and $\mathrm{MoS}_{2}$ but Lince et al. did not. Lince et al. attributed this to the potential oxidation of Ti by the deposition in a poorer vacuum environment. More recent investigations published by McDonnell et al. [18]. and Smyth et al. [24,67,75]. demonstrate that the chamber pressure during contact deposition, a process parameter that is typically unreported in device papers, has a measurable impact on the chemistry of the interface. In addition to affecting the concentration of carbon in the metal film or at the interface, the base pressure determines which chemical states will be present at the metal-TMDC interface. In the case of Ti, for example, the presence of oxidizing species in $\mathrm{HV}$ deposition chambers prevents chemical reactions between Ti and $\mathrm{MoS}_{2}$ as Ti instead reacts with these molecules to form $\mathrm{TiO}_{2}$ [18]. This is illustrated in Figure 4a. The author noted, that when Ti was deposited in $\mathrm{HV}$, the $\mathrm{MoS}_{2}$ did not exhibit changes in its chemical state. However, in UHV, the expected formation of metallic Mo and titanium sulfides was found in agreement with McGovern et al. [16]. The authors proposed that under HV conditions, there is a sufficient partial pressure of oxidizing species present that they will be impinge on the surface of $\mathrm{MoS}_{2}$ at rates comparable to a monolayer per second. With Ti deposition rates on the same order of magnitude, this essentially amounts to a co-deposition of Ti and Oxygen when the deposition is 
carried out in HV. The differences between HV and UHV depositions are illustrated schematically in Figure 4b. XPS was used to verify that Ti deposition in HV can be completed oxidized (inset of Figure 4a). More recent work by Freedy et al. [73] further tested this hypothesis by examining the Ti chemistry as a function of vacuum pressure and deposition rate in HV. These result (shown in Figure 4c) showed that the Ti metal to Ti oxide ratio could be readily altered by varying either vacuum pressure or Ti deposition rate, which is consistent with the model proposed by McDonnell et al. [18].
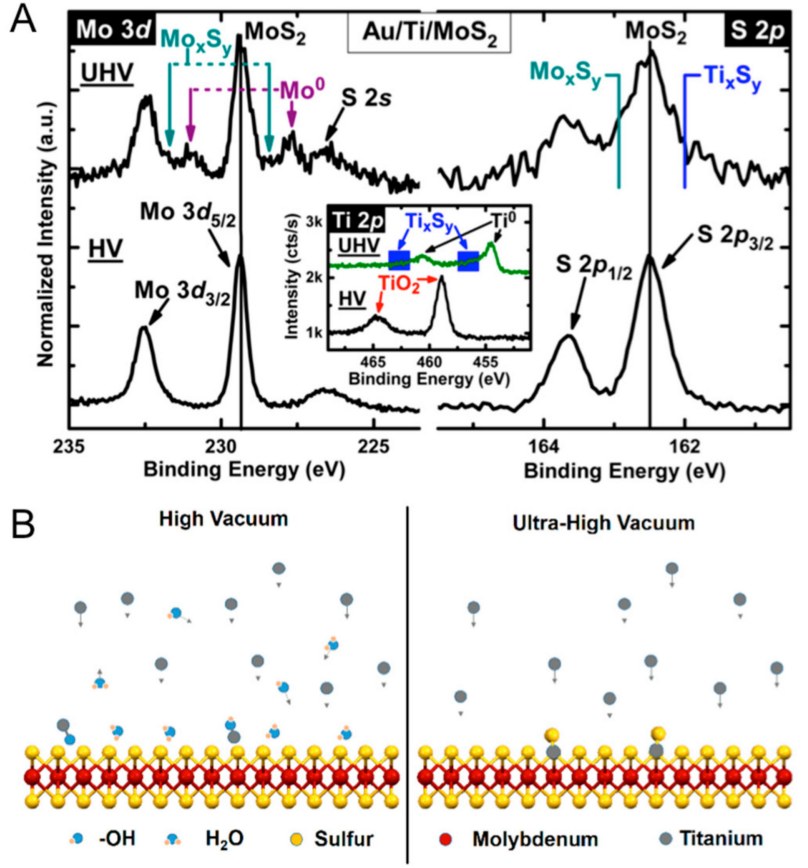

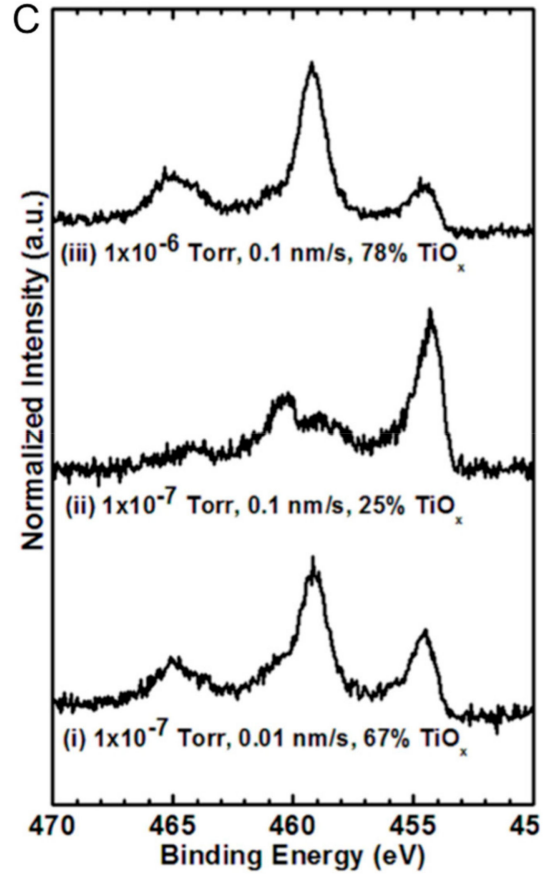

Figure 4. (A) Mo 3d, S 2p, and Ti 2p (inset) for UHV Ti-MoS 2 exposed to air for 20 minutes. The new high binding energy features in the Ti $2 p$ spectra can be attributed to partial oxidation of some of the titanium species. However, the presence of $\mathrm{Ti}_{\mathrm{x}} \mathrm{S}_{\mathrm{y}}$ is still clearly detected in all three core-levels. (B) schematic of depositions in high vacuum (HV) with oxidizing species present versus ultra-high vacuum (UHV) with no such species present. (C) Ti $2 p$ core-level spectra for Ti deposited onto samples cut from a single $\mathrm{Gr}-\mathrm{SiO}_{2}$ sample at different deposition conditions resulting in different oxide compositions. Parts A and B Reprinted and adapted with permission from McDonnell et al. ACS Applied Materials \& Interfaces 8, 8289-8294 (2016). Copyright (2016) American Chemical Society. Part C Reprinted and adapted with permission from Freedy et al. Nanotechnology 29, 145201 (2018). Copyright (2018) IOP Publishing Ltd.

\subsection{Engineering the Interface}

One method for controlling interface chemistry is to decouple the metal contact from the TMDC via an interfacial oxide layer. Improvements in electrical contact resistance, device stability, on-current, and mobility via this method using $\mathrm{Ti}^{-\mathrm{TiO}_{2}}$ contacts have been demonstrated in a number of publications [76-79]. The success of the interfacial oxide approach has been attributed to Fermi level de-pinning by Park et al. [76] and Kim et al. [78] by electrical measurements of the Schottky barrier height. The presence of an oxide is said to block the penetration of the metal wave function into the semiconductor, preventing metal-induced gap states which pin the Fermi level. Another possible mechanism discussed by Kaushik et al. [79] is the lowering of the electron Schottky barrier due to n-type charge-transfer doping from the oxide to $\mathrm{MoS}_{2}$. The effects of interfacial oxide on interface chemistry and transport properties was recently expanded on by Freedy et al. [80].

By employing in-situ UHV Ti deposition and characterization of $\mathrm{MoS}_{2}$, Freedy et al. [80] were able to use partial pressures of $\mathrm{O}_{2}$ during deposition in order to protect the $\mathrm{MoS}_{2}$. The resultant $\mathrm{TiO}_{\mathrm{x}}$ thin films were deposited by deliberate reactive e-beam of Ti rather than the accidental reactive e-beam that 
takes place in $\mathrm{HV}$ reactors. The authors showed that even a thin $1 \mathrm{~nm}$ layer of $\mathrm{TiO}_{\mathrm{x}}$ was sufficient to protect the $\mathrm{MoS}_{2}$ interface from reactions, and that subsequent Ti deposition could be carried out with no oxygen to ensure that the remainder and topmost portion of the contact is metallic Ti. By using the ex-situ thermal characterization techniques of time dependent thermoreflectance (TDTR), the authors were able to show how important such a Ti-TiO $-\mathrm{MoS}_{2}$ structure may be for Ti contact adhesion layers.

Like contact resistance, thermal boundary conductance is an important property for nanoelectronic devices. This is because heat dissipation is a major issue in transistors and low boundary conductances can lead to localized heating of the devices, compromising performance and reliability. In a typical $\mathrm{Au}-\mathrm{Ti}-\mathrm{MoS}_{2}$ stack, it is now known that deposition of contacts in UHV will lead to Ti-MoS 2 reactions that limit device performance [18,19]. In the recent work of Freedy et al. [80] it was shown that, while the $\mathrm{Au}-\mathrm{TiO}_{\mathrm{x}}-\mathrm{MoS}_{2}$ structure prevented reactions at the $\mathrm{Ti}-\mathrm{MoS}_{2}$ interface, the thermal boundary conductance was markedly lower than that of the Au-Ti-MoS $\mathrm{M}_{2}$ structure. This is shown in Figure 5. However, utilizing a $\mathrm{Au}-\mathrm{Ti}-\mathrm{TiO}_{\mathrm{x}}-\mathrm{MoS}_{2}$ structure yielded a protected $\mathrm{MoS}_{2}$ interface while providing comparable thermal boundary conductance to the Au-Ti-MoS 2 structure. This work showed that the metal-adhesion layer interface can be critical to heat dissipation and should not be overlooked. Furthermore, the use of a metal-oxide heterostructure $\left(\mathrm{Ti}^{-} \mathrm{TiO}_{\mathrm{x}}\right)$ adhesion preserved both the semiconductor chemistry and the thermal transport properties of the contact, offering a practical engineering solution for $\mathrm{MoS}_{2}$ contacts.
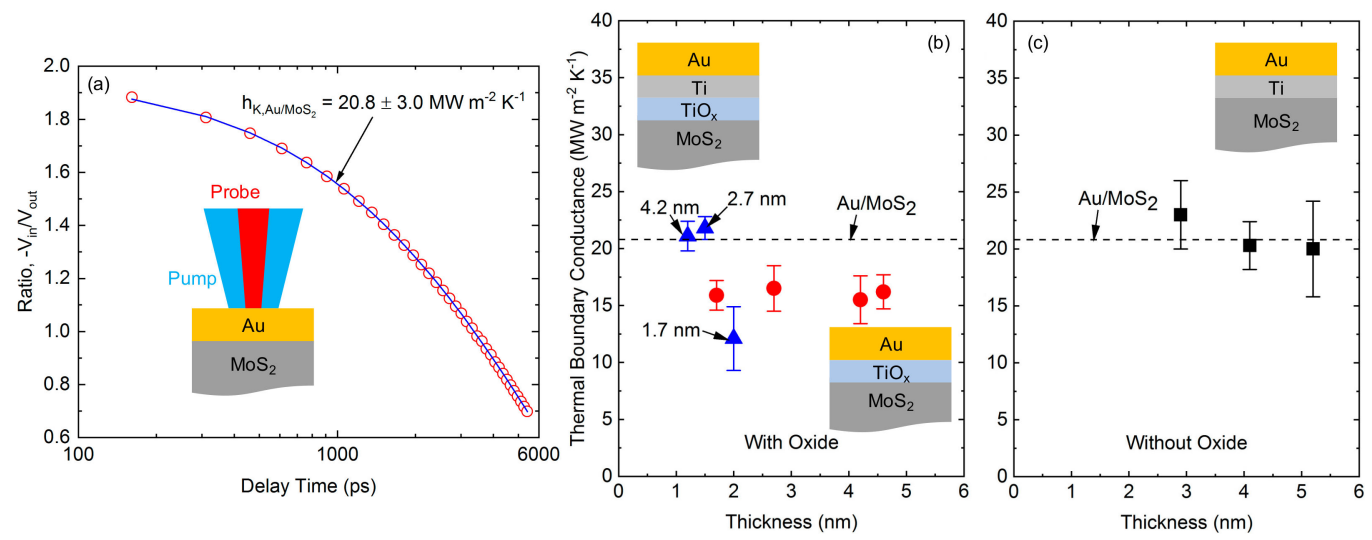

Figure 5. (a) TDTR data and best fit for the $\mathrm{Au}-\mathrm{MoS}_{2}$ structure. Thermal boundary conductance as a function of interfacial layer thickness for the $\mathrm{MoS}_{2}$ substrates (b) with and (c) without an oxide interlayer. Samples included are $\mathrm{Au}-\mathrm{Ti}$ (black squares), $\mathrm{Au}-\mathrm{TiO}_{\mathrm{x}}$ (red circles), and $\mathrm{Au}-\mathrm{Ti}-\mathrm{TiO}_{\mathrm{x}}$ (blue triangles) in addition to a reference sample of $\mathrm{Au}-\mathrm{MoS}_{2}$ (dashed line). The arrows indicate the $\mathrm{Ti}$ metal thickness for each $\mathrm{Ti}-\mathrm{TiO}_{\mathrm{x}}$ sample where data are plotted as a function of oxide thickness. Reprinted with permission from Freedy et al., Phys Rev Materials, 3, 104001 (2019), DOI: 10.1103/PhysRevMaterials.3.104001 Copyright (2019) by the American Physical Society.

\subsection{Thermal Stability}

Annealing the device after contact deposition is common practice in device processing and notable changes in device transport properties after annealing have been observed. $[19,35,75,81,82]$ English et al. report that post-deposition annealing reduces hysteresis and stabilizes electrical measurements for $\mathrm{Au}$ contacted FETs [19]. Baugher et al. claim that vacuum annealing of devices with Ti-Au contacts eliminated all Schottky behavior [82]. Abraham and Mohney observe decreased contact resistance by rapid thermal annealing of $\mathrm{MoS}_{2}$ FETs with Ag contacts [35]. The improvement is speculated to be due to the diffusion of $\mathrm{Ag}$ into $\mathrm{MoS}_{2}$, resulting in local doping under the contact, which would be consistent with prior reports from Li et al. [38] of Ag diffusion into $\mathrm{MoS}_{2}$ at temperatures $>326^{\circ} \mathrm{C}$. Liu et al. [83] show a current improvement of two orders of magnitude after vacuum annealing $\mathrm{WS}_{2}$ FETs with Ti-Au contacts, stating that annealing enhances contact adhesion. In all of the examples mentioned, chemical characterization of the interface is lacking while the observed improvements are almost 
certainly correlated with changes in interface chemistry. Recently, Smyth et al. [75] reported substantial improvement after annealing WSe $\mathrm{W}_{2}$ FETs contacted with Pd. They find that annealing $\mathrm{Pd}_{-} \mathrm{WSe}_{2}$ in forming gas at $400{ }^{\circ} \mathrm{C}$ drives the formation of $\mathrm{PdSe}_{\mathrm{x}}$ which results in Ohmic band alignment. They also note that annealing in UHV results in a smaller composition of $\mathrm{PdSe}_{\mathrm{x}}$ and a higher Schottky barrier in comparison with annealing in forming gas. It is clear that post-deposition annealing conditions also play an important role in determining contact properties.

In the previously described study of $\mathrm{Cr}$ on $\mathrm{MoS}_{2}$ by Durbin et al. [26], it was shown that $\mathrm{Cr}$ is reactive with $\mathrm{MoS}_{2}$ at room temperature forming metallic Mo and Cr-S, and that heating the material following deposition resulted in an increase in the reaction products. By varying the incident photon energy, they acquired a non-destructive depth profile and concluded that the resultant structure consisted of $\mathrm{MoS}_{2}$ covered with a clustered or islanded Cr-Mo alloy, covered with a Cr-S film that possibly contained $\mathrm{Cr}$ metal, and was terminated with a sulfur rich $\mathrm{Cr}-\mathrm{S}$ surface. Lince et al. [29,30] report similar behavior for $\mathrm{Mn}$ on $\mathrm{MoS}_{2}$, with the reaction driven to completion by $497^{\circ} \mathrm{C}$ followed by $\mathrm{Mn}$ agglomeration at $767^{\circ} \mathrm{C}$. Unlike $\mathrm{Mn}$, Fe was found to delaminate from the $\mathrm{MoS}_{2}$ surface as a result of annealing. These studies illustrate the differences in the behavior of reactive ( $\mathrm{Cr}$ and $\mathrm{Mn})$ vs. non-reactive ( $\mathrm{Fe}$ ) metals on $\mathrm{MoS}_{2}$ after thermal annealing. As mentioned in relation to the device studies of Ag-MoS 2 contacts by Abraham and Mohney [35] the prior work by Li et al. [38] had shown that Ag diffused into $\mathrm{MoS}_{2}$ at temperature $>326^{\circ} \mathrm{C}$ and that there was an associated charge transfer from $\mathrm{Ag}$ to $\mathrm{MoS}_{2}$ detected by XPS binding energy shifts. Notably, this shift reversed itself after annealing to $526^{\circ} \mathrm{C}$ and $\mathrm{Ag}$ clusters formed after annealing to $577^{\circ} \mathrm{C}$.

In recent work by Freedy et al. $[69,84]$ the stability of the metal-MoS ${ }_{2}$ interface has been considered. In particular, the Ti-MoS 2 interface which forms in UHV was studied as a function of annealing temperature. The authors found that detectable concentration of metallic Mo and $\mathrm{TiS}_{\mathrm{x}}$ species increased after anneals as low as $100{ }^{\circ} \mathrm{C}$ (the lowest temperature employed in the study) which is reproduced in Figure 6. This would suggest that such contact would not be stable during back-end process and may in fact be unstable during some operating conditions. This result may explain why Radisavljevic reports that $\mathrm{Au}-\mathrm{Ti}$ contact performed better before annealing [14].
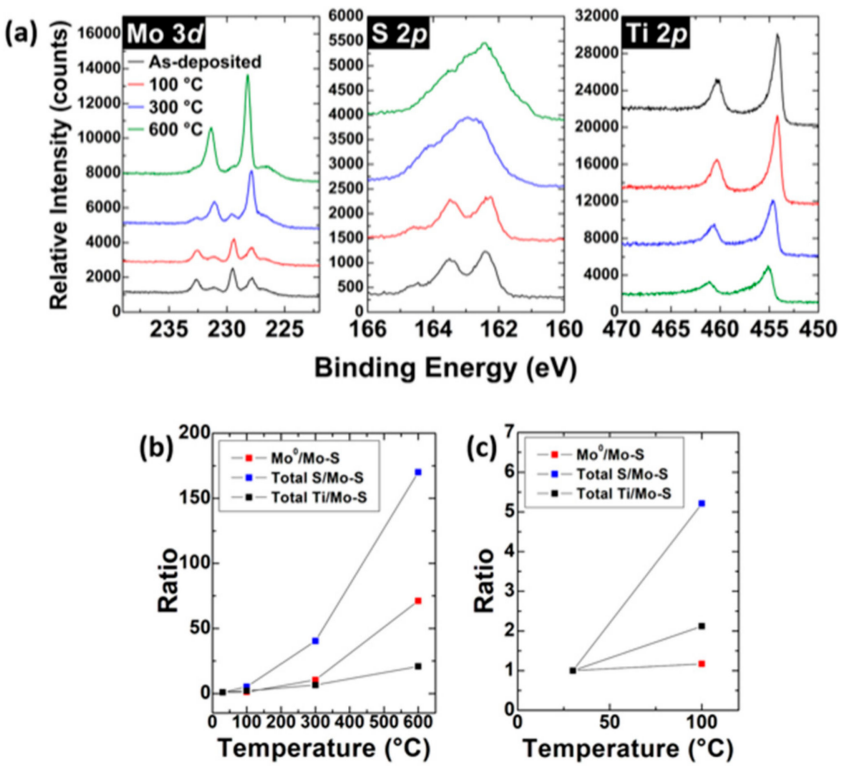

Figure 6. (a) XPS spectra acquired following $30 \mathrm{~min}$ anneals at each temperature. These were performed sequentially on the same sample. (b) Intensity ratios based on the data in (a) where (c) highlights the changes that occur at $100{ }^{\circ} \mathrm{C}$. Reprinted with permission from Freedy et al. ACS Appl. Mater. Inter. 11(38) 35389, (2019). Copyright (2019) American Chemical Society. 
This work also investigated the structure and composition profile across the interface before and after annealing at $400^{\circ} \mathrm{C}$ by high-resolution transmission electronic microscopy (HRTEM). The initial result was similar to that reported by Wu et al. [17] and showed that the Ti diffuses into the $\mathrm{MoS}_{2}$ However, additional information about the Ti metal region was gathered and it was shown that the Mo and $S$ also diffuse outward into the Ti layer. The HRTEM acquired after annealing are reproduced in Figure 7. Following annealing, there is a clear Mo rich region that separated the region of $\mathrm{MoS}_{2}$ (with Ti impurities) and Ti (with Mo and S impurities). Also observed is clear evidence of recrystallization in the $\mathrm{MoS}_{2}$ region that was disturbed by Ti diffusion. Whether this is $\mathrm{MoS}_{2}$, TiS 2 or MoTiS 2 cannot be conclusively determined at this time.

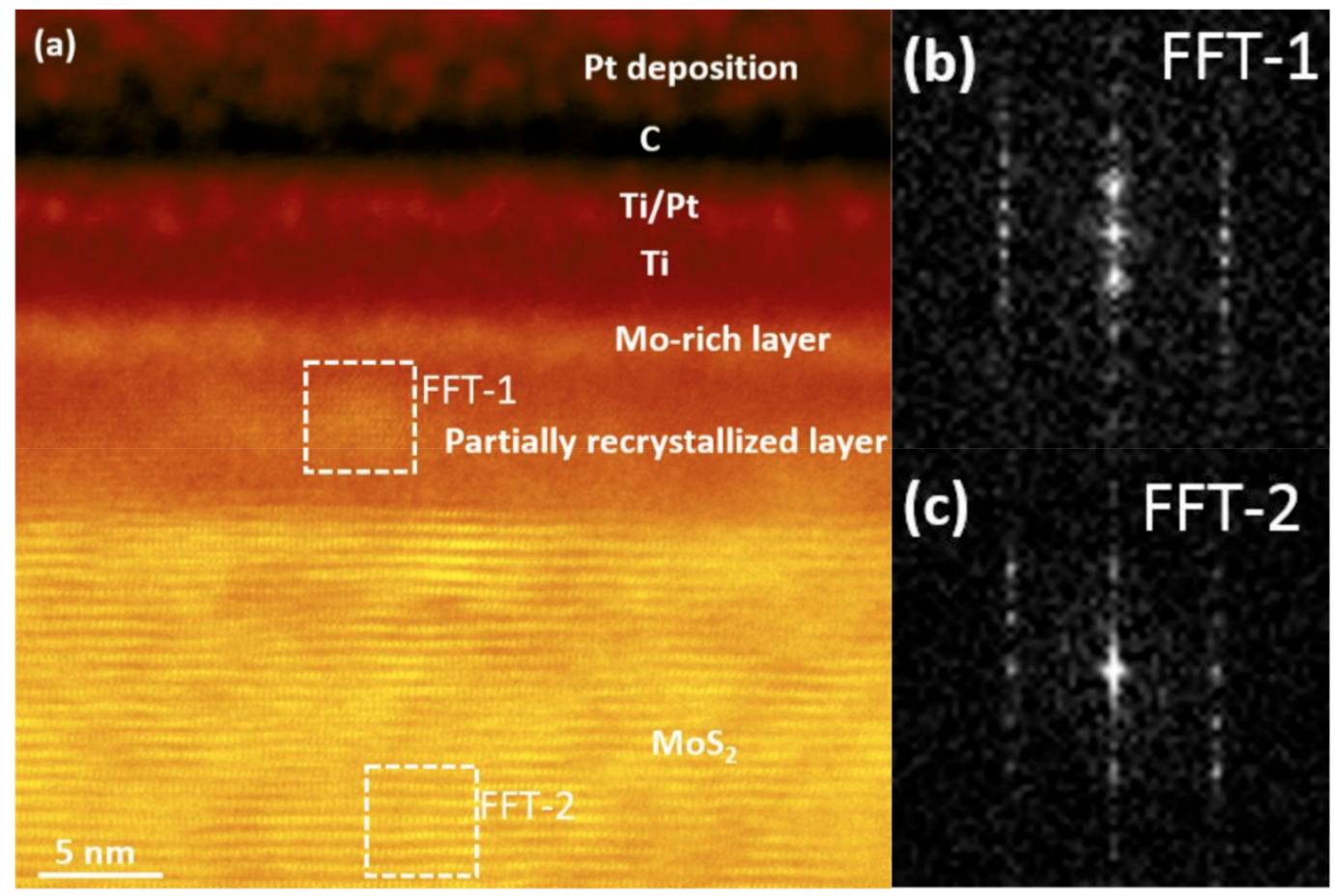

Figure 7. (a) Cross-sectional ADF-STEM image of Ti-MoS 2 after $30 \mathrm{~min}$ anneal at $400{ }^{\circ} \mathrm{C}$ showing a Mo-rich layer and a partially recrystallized layer grown out from the disordered Mo/S-rich layer, (b) and (c) are FFT images of the white dotted-line framed regions in (a). Reprinted with permission from Freedy et al. ACS Appl. Mater. Inter. 11(38) 35389, (2019). Copyright (2019) American Chemical Society.

\section{Conclusions}

A substantial volume of recent work in the literature is focused on the synthesis and characterization of 2D materials and on the fabrication and characterization of devices using 2D materials. Some studies have focused on optimizing transport properties of 2D-contact interface while a very small number of recent papers have specifically examined the chemistry of the interface. There exists a gap between these two topics of research, resulting in a lack of understanding of the relationship between contact processing, interface chemistry, and electrical and thermal transport properties. While the reactive nature of the metal-2D interface has been previously documented, the chemical composition of the interface and effects of processing has only very recently been explored in greater detail for the Ti-MoS 2 interface. Recent work discussed in this review has demonstrated that various aspects of processing, such as deposition conditions and post-deposition annealing, can have drastic effects on interface chemistry and transport properties. This provides a more complete approach to the interpretation of the behavior of electronic devices, particularly when discrepancies are observed between theory and experiment or between experiments as summarized in Table 2. Furthermore, control over interface chemistry during processing opens doors for interface engineering, which can be implemented to tailor 
thermal and electrical transport across interfaces to meet device-specific requirements and expand the field of 2D nanoelectronics into new domains.

Table 2. Summary of property variability reported and possible explanations.

\begin{tabular}{|c|c|c|c|c|c|}
\hline & Ref & Property & Ref & Property & Suggested Explanation \\
\hline $\begin{array}{l}\text { Metal induced } \\
\text { doping in } \mathrm{MoS}_{2}\end{array}$ & {$[25]$} & $\begin{array}{l}\text { n-type Pd-MoS } \\
\text { interface }\end{array}$ & {$[64]$} & $\begin{array}{l}\text { p-type Pd-MoS } \\
\text { interface }\end{array}$ & $\begin{array}{l}\mathrm{MoS}_{2} \text { variability, since } \mathrm{Au} \text { on } \mathrm{MoS}_{2} \text { can exhibit both } \\
\text { n-type and p-type contact behavior. [23] }\end{array}$ \\
\hline
\end{tabular}

Conflicts of Interest: The authors declare no conflict of interest.

\section{References}

1. Wilson, J.A.; Yoffe, A.D. Transition metal dichalcogenides discussion and interpretation of observed optical, electrical and structural properties. Adv. Phys. 1969, 18, 193-335. [CrossRef]

2. Tributsch, H.; Bennett, J. Electrochemistry and photochemistry of $\mathrm{MoS}_{2}$ layer crystals. I. J. Electroanal. Chem. Interf. Electrochem. 1977, 81, 97-111. [CrossRef]

3. Kautek, W.; Gerischer, H. Photoelectrochemical Reactions and Formation of Inversion Layers at n-Type $\mathrm{MoS}_{2^{-}}, \mathrm{MoSe}_{2^{-}}$, and WSe ${ }_{2}$-Electrodes in Aprotic Solvents. Berichte der Bunsengesellschaft für physikalische Chemie 1980, 84, 645-653. [CrossRef]

4. Kautek, W.; Gerischer, H.; Tributsch, H. The role of carrier diffusion and indirect optical transitions in the photoelectrochemical behavior of layer type d-band semiconductors. J. Electrochem. Soc. 1980, 127, 2471-2478. [CrossRef]

5. Fortin, E.; Sears, W. Photovoltaic effect and optical absorption in MoS 2 . J. Phys. Chem. Solid 1982, 43, 881-884. [CrossRef]

6. Boehm, H.; Clauss, A.; Fischer, G.; Hofmann, U. Dünnste kohlenstoff-folien. Zeitschrift Für Naturforschung B 1962, 17, 150-153. [CrossRef]

7. Joensen, P.; Frindt, R.; Morrison, S.R. Single-layer MoS 2 . Mater. Res. Bull. 1986, 21, 457-461. [CrossRef]

8. Novoselov, K.; Geim, A.K.; Morozov, S.; Jiang, D.; Zhang, Y.; Dubonos, S.; Grigorieva, I.; Firsov, A. Electric field effect in atomically thin carbon films. Science 2004, 306, 666-669. [CrossRef]

9. Novoselov, K.; Jiang, D.; Schedin, F.; Booth, T.; Khotkevich, V.; Morozov, S.; Geim, A. Two-dimensional atomic crystals. Proc. Natl. Acad. Sci. USA 2005, 102, 10451-10453. [CrossRef]

10. Zhang, Y.; Tan, Y.-W.; Stormer, H.L.; Kim, P. Experimental observation of the quantum Hall effect and Berry's phase in graphene. Nature 2005, 438, 201-204. [CrossRef]

11. Xu, M.; Liang, T.; Shi, M.; Chen, H. Graphene-like two-dimensional materials. Chem. Rev. 2013, 113, 3766-3798. [CrossRef] [PubMed]

12. Gupta, A.; Sakthivel, T.; Seal, S. Recent development in 2D materials beyond graphene. Prog. Mater. Sci. 2015, 73, 44-126. [CrossRef]

13. Jiang, L.; Marconcini, P.; Hossian, M.S.; Qiu, W.; Evans, R.; Macucci, M.; Skafidas, E. A tight binding and [... formula...] study of monolayer stanene. Sci. Rep. 2017, 7, 12069. [CrossRef] [PubMed]

14. Radisavljevic, B.; Radenovic, A.; Brivio, J.; Giacometti, V.; Kis, A. Single-layer $\mathrm{MoS}_{2}$ transistors. Nat. Nanotech. 2011, 6, 147-150. [CrossRef] [PubMed]

15. McDonnell, S.J.; Wallace, R.M. UV-Ozone Functionalization of 2D Materials. JOM 2019, 71, $224-237$. [CrossRef]

16. McGovern, I.T.; Dietz, E.; Rotermund, H.H.; Bradshaw, A.M.; Braun, W.; Radlik, W.; McGilp, J.F. Soft X-ray photoemission spectroscopy of metal-molybdenum bisulphide interfaces. Surf. Sci. 1985, 152, 1203-1212. [CrossRef] 
17. Wu, R.J.; Udyavara, S.; Ma, R.; Wang, Y.; Chhowalla, M.; Koester, S.J.; Neurock, M.; Mkhoyan, K.A. An Inside Look at the Ti-MoS 2 Contact in Ultra-thin Field Effect Transistor with Atomic Resolution. arXiv preprint 2018, arXiv:1807.01377.

18. McDonnell, S.; Smyth, C.; Hinkle, C.L.; Wallace, R.M. $\mathrm{MoS}_{2}$-Titanium Contact Interface Reactions. ACS Appl. Mater. Interf. 2016, 8, 8289-8294. [CrossRef]

19. English, C.D.; Shine, G.; Dorgan, V.E.; Saraswat, K.C.; Pop, E. Improved Contacts to MoS 2 Transistors by Ultra-High Vacuum Metal Deposition. Nano Lett. 2016, 16, 3824-3830. [CrossRef]

20. Das, S.; Chen, H.-Y.; Penumatcha, A.V.; Appenzeller, J. High Performance Multilayer $\mathrm{MoS}_{2}$ Transistors with Scandium Contacts. Nano Lett. 2013, 13, 100-105. [CrossRef]

21. Kamaratos, M.; Papageorgopoulos, C. A study of the behavior of Fe and Ni on $\mathrm{MoS}_{2}$. Solid State Comm. 1984, 49, 715-718. [CrossRef]

22. Papageorgopoulos, C.; Kamaratos, M. Adsorption studies of Ni on $\mathrm{MoS}_{2}$ and $\mathrm{O}_{2}$ on Ni-covered $\mathrm{MoS}_{2}$. Surf. Sci. 1985, 164, 353-366. [CrossRef]

23. McDonnell, S.; Addou, R.; Buie, C.; Wallace, R.M.; Hinkle, C.L. Defect-dominated doping and contact resistance in $\mathrm{MoS}_{2}$. ACS Nano 2014, 8, 2880-2888. [CrossRef] [PubMed]

24. Smyth, C.M.; Addou, R.; McDonnell, S.; Hinkle, C.L.; Wallace, R.M. Contact Metal-MoS 2 Interfacial Reactions and Potential Implications on $\mathrm{MoS}_{2}$-Based Device Performance. J. Phys. Chem. C 2016, 120, 14719-14729. [CrossRef]

25. Kaushik, N.; Nipane, A.; Basheer, F.; Dubey, S.; Grover, S.; Deshmukh, M.M.; Lodha, S. Schottky barrier heights for Au and Pd contacts to $\mathrm{MoS}_{2}$. Appl. Phys. Lett. 2014, 105, 113505. [CrossRef]

26. Durbin, T.D.; Lince, J.R.; Didziulis, S.V.; Shuh, D.K.; Yarmoff, J.A. Soft X-ray photoelectron spectroscopy study of the interaction of Cr with $\mathrm{MoS}_{2}$ (0001). Surf. Sci. 1994, 302, 314-328. [CrossRef]

27. Durbin, T.D.; Lince, J.R.; Yarmoff, J.A. Chemical interaction of thin Cr films with the $\mathrm{MoS}_{2}(0001)$ surface studied by x-ray photoelectron spectroscopy and scanning Auger microscopy. J. Vac. Sci. Technol. A 1992, 10, 2529-2534. [CrossRef]

28. Lince, J.R.; Carré, D.J.; Fleischauer, P.D. Schottky-barrier formation on a covalent semiconductor without Fermi-level pinning: The metal-MoS 2 interface. Phys. Rev. B 1987, 36, 1647-1656. [CrossRef]

29. Lince, J.R.; Stewart, T.B.; Fleischauer, P.D.; Yarmoff, J.A.; Taleb-Ibrahimi, A. The chemical interaction of Mn with the $\mathrm{MoS}_{2}$ (0001) surface studied by high-resolution photoelectron spectroscopy. J. Vac. Sci. Technol. A 1989, 7, 2469-2474. [CrossRef]

30. Lince, J.R.; Stewart, T.B.; Hills, M.M.; Fleischauer, P.D.; Yarmoff, J.A.; Taleb-Ibrahimi, A. Photoelectron spectroscopic study of the interaction of thin Fe films with the $\mathrm{MoS}_{2}(0001)$ surface. Surf. Sci. 1989, 223, 65-81. [CrossRef]

31. Kamaratos, M.; Papageorgopoulos, C. Intercalation of $\mathrm{MoS}_{2}(0001)$ with Fe, Ni and Pd. Solid State Comm. 1987, 61, 567-569. [CrossRef]

32. Dong, H.; Gong, C.; Addou, R.; McDonnell, S.; Azcatl, A.; Qin, X.; Wang, W.; Wang, W.; Hinkle, C.L.; Wallace, R.M. Schottky Barrier Height of Pd/MoS 2 Contact by Large Area Photoemission Spectroscopy. ACS Appl. Mater. Interf. 2017, 9, 38977-38983. [CrossRef] [PubMed]

33. Shimazu, Y.; Arai, K.; Iwabuchi, T. Contact-induced doping in aluminum-contacted molybdenum disulfide. Jap. J. Appl. Phys. 2017, 57, 015801. [CrossRef]

34. Kang, J.; Liu, W.; Banerjee, K. High-performance $\mathrm{MoS}_{2}$ transistors with low-resistance molybdenum contacts. Appl. Phys. Lett. 2014, 104, 093106. [CrossRef]

35. Abraham, M.; Mohney, S.E. Annealed Ag contacts to $\mathrm{MoS}_{2}$ field-effect transistors. J. Appl. Phys. 2017, 122, 115306. [CrossRef]

36. Yuan, H.; Cheng, G.; You, L.; Li, H.; Zhu, H.; Li, W.; Kopanski, J.J.; Obeng, Y.S.; Hight Walker, A.R.; Gundlach, D.J.; et al. Influence of Metal-MoS 2 Interface on $\mathrm{MoS}_{2}$ Transistor Performance: Comparison of Ag and Ti Contacts. ACS Appl. Mater. Interf. 2015, 7, 1180-1187. [CrossRef]

37. Souder, A.; Brodie, D. Electrical contacts and conductivity of $\mathrm{MoS}_{2}$ layer structures. Can. J. Phys. 1971, 49, 2565-2571. [CrossRef]

38. Li, S.Y.; Rodriguez, J.A.; Hrbek, J.; Huang, H.H.; Xu, G.Q. Chemical and electronic properties of silver atoms supported on sulfur and molybdenum sulfide surfaces. Surf. Sci. 1998, 395, 216-228. [CrossRef] 
39. Cheon, G.; Duerloo, K.-A.N.; Sendek, A.D.; Porter, C.; Chen, Y.; Reed, E.J. Data mining for new two-and one-dimensional weakly bonded solids and lattice-commensurate heterostructures. Nano Lett. 2017, 17, 1915-1923. [CrossRef]

40. Voiry, D.; Salehi, M.; Silva, R.; Fujita, T.; Chen, M.; Asefa, T.; Shenoy, V.B.; Eda, G.; Chhowalla, M. Conducting $\mathrm{MoS}_{2}$ Nanosheets as Catalysts for Hydrogen Evolution Reaction. Nano Lett. 2013, 13, 6222-6227. [CrossRef]

41. Lukowski, M.A.; Daniel, A.S.; Meng, F.; Forticaux, A.; Li, L.; Jin, S. Enhanced hydrogen evolution catalysis from chemically exfoliated metallic $\mathrm{MoS}_{2}$ nanosheets. J. Am. Chem. Soc. 2013, 135, 10274-10277. [CrossRef] [PubMed]

42. Chang, K.; Hai, X.; Pang, H.; Zhang, H.; Shi, L.; Liu, G.; Liu, H.; Zhao, G.; Li, M.; Ye, J. Targeted Synthesis of 2H-and 1T-Phase $\mathrm{MoS}_{2}$ Monolayers for Catalytic Hydrogen Evolution. Adv. Mater. 2016, 28, 10033-10041. [CrossRef] [PubMed]

43. Kappera, R.; Voiry, D.; Yalcin, S.E.; Branch, B.; Gupta, G.; Mohite, A.D.; Chhowalla, M. Phase-engineered low-resistance contacts for ultrathin $\mathrm{MoS}_{2}$ transistors. Nat. Mater. 2014, 13, 1128-1134. [CrossRef] [PubMed]

44. Toh, R.J.; Sofer, Z.; Luxa, J.; Sedmidubský, D.; Pumera, M. 3R phase of $\mathrm{MoS}_{2}$ and $\mathrm{WS}_{2}$ outperforms the corresponding $2 \mathrm{H}$ phase for hydrogen evolution. Chem. Comm. 2017, 53, 3054-3057. [CrossRef] [PubMed]

45. McDonnell, S.J.; Wallace, R.M. Atomically-Thin Layered Films for Device Applications based upon 2D TMDC Materials. Thin Solid Films 2016, 616, 482-501. [CrossRef]

46. Lin, Z.; McCreary, A.; Briggs, N.; Subramanian, S.; Zhang, K.; Sun, Y.; Li, X.; Borys, N.J.; Yuan, H.; Fullerton-Shirey, S.K.; et al. 2D materials advances: From large scale synthesis and controlled heterostructures to improved characterization techniques, defects and applications. 2D Mater. 2016, 3, 042001. [CrossRef]

47. Kaul, A.B. Two-dimensional layered materials: Structure, properties, and prospects for device applications. J. Mater. Res. 2014, 29, 348-361. [CrossRef]

48. Jariwala, D.; Sangwan, V.K.; Lauhon, L.J.; Marks, T.J.; Hersam, M.C. Emerging Device Applications for Semiconducting Two-Dimensional Transition Metal Dichalcogenides. ACS Nano 2014, 8, 1102-1120. [CrossRef]

49. Bernal, M.M.; Milano, D. Two-dimensional nanomaterials via liquid-phase exfoliation: synthesis, properties and applications. In Carbon Nanotechnology; Milne, W.I., Cole, M., Eds.; One Central Press (OCP): Cheshire, UK, 2014; pp. 159-185.

50. Gao, M.-R.; Xu, Y.-F.; Jiang, J.; Yu, S.-H. Nanostructured metal chalcogenides: synthesis, modification, and applications in energy conversion and storage devices. Chem. Soc. Rev. 2013, 42, 2986-3017. [CrossRef]

51. Wang, Q.H.; Kalantar-Zadeh, K.; Kis, A.; Coleman, J.N.; Strano, M.S. Electronics and optoelectronics of two-dimensional transition metal dichalcogenides. Nat. Nanotechnol. 2012, 7, 699-712. [CrossRef]

52. Fiori, G.; Bonaccorso, F.; Iannaccone, G.; Palacios, T.; Neumaier, D.; Seabaugh, A.; Banerjee, S.K.; Colombo, L. Electronics based on two-dimensional materials. Nat. Nanotechnol. 2014, 9, 768-779. [CrossRef] [PubMed]

53. Walsh, L.A.; Hinkle, C.L. van der Waals epitaxy: 2D materials and topological insulators. Appl. Mater. Today 2017, 9, 504-515. [CrossRef]

54. Du, Y.; Yang, L.; Liu, H.; Ye, P.D. Contact research strategy for emerging molybdenum disulfide and other two-dimensional field-effect transistors. APL Mater. 2014, 2, 092510. [CrossRef]

55. Zhang, Z.; Yates, J.T. Band Bending in Semiconductors: Chemical and Physical Consequences at Surfaces and Interfaces. Chem. Rev. 2012, 112, 5520-5551. [CrossRef]

56. Streetman, B.G.; Banerjee, S. Solid State Electronic Devices; Pearson Education Limited: London, UK, 2015.

57. Chuang, H.-J.; Chamlagain, B.; Koehler, M.; Perera, M.M.; Yan, J.; Mandrus, D.; Tománek, D.; Zhou, Z. Low-resistance 2D/2D ohmic contacts: A universal approach to high-performance WSe $2, \mathrm{MoS}_{2}$, and $\mathrm{MoSe}_{2}$ transistors. Nano Lett. 2016, 16, 1896-1902. [CrossRef]

58. Suh, J.; Park, T.-E.; Lin, D.-Y.; Fu, D.; Park, J.; Jung, H.J.; Chen, Y.; Ko, C.; Jang, C.; Sun, Y.; et al. Doping against the Native Propensity of $\mathrm{MoS}_{2}$ : Degenerate Hole Doping by Cation Substitution. Nano Lett. 2014, 14, 6976-6982. [CrossRef]

59. Wang, Y.; Yang, R.X.; Quhe, R.; Zhong, H.; Cong, L.; Ye, M.; Ni, Z.; Song, Z.; Yang, J.; Shi, J.; et al. Does p-type ohmic contact exist in $\mathrm{WSe}_{2}-$ metal interfaces? Nanoscale 2016, 8, 1179-1191. [CrossRef]

60. Kim, C.; Moon, I.; Lee, D.; Choi, M.S.; Ahmed, F.; Nam, S.; Cho, Y.; Shin, H.-J.; Park, S.; Yoo, W.J. Fermi Level Pinning at Electrical Metal Contacts of Monolayer Molybdenum Dichalcogenides. ACS Nano 2017, 11, 1588-1596. [CrossRef] 
61. Kang, J.; Liu, W.; Sarkar, D.; Jena, D.; Banerjee, K. Computational Study of Metal Contacts to Monolayer Transition-Metal Dichalcogenide Semiconductors. Phys. Rev. X 2014, 4, 031005. [CrossRef]

62. Gong, C.; Colombo, L.; Wallace, R.M.; Cho, K. The Unusual Mechanism of Partial Fermi Level Pinning at Metal-MoS 2 Interfaces. Nano Lett. 2014, 14, 1714-1720. [CrossRef]

63. Allain, A.; Kang, J.; Banerjee, K.; Kis, A. Electrical contacts to two-dimensional semiconductors. Nat. Mater. 2015, 14, 1195-1205. [CrossRef] [PubMed]

64. Fontana, M.; Deppe, T.; Boyd, A.K.; Rinzan, M.; Liu, A.Y.; Paranjape, M.; Barbara, P. Electron-hole transport and photovoltaic effect in gated $\mathrm{MoS}_{2}$ Schottky junctions. Sci. Rep. 2013, 3, 1634. [CrossRef] [PubMed]

65. Heine, V. Theory of Surface States. Phys. Rev. 1965, 138, A1689-A1696. [CrossRef]

66. Hasegawa, H.; Sawada, T. On the electrical properties of compound semiconductor interfaces in metal/insulator/ semiconductor structures and the possible origin of interface states. Thin Solid Films 1983, 103, 119-140. [CrossRef]

67. Smyth, C.M.; Addou, R.; McDonnell, S.; Hinkle, C.L.; Wallace, R.M. WSe $e_{2}$-contact metal interface chemistry and band alignment under high vacuum and ultra high vacuum deposition conditions. 2D Mater. 2017, 4, 025084. [CrossRef]

68. McDonnell, S.; Azcatl, A.; Addou, R.; Gong, C.; Battaglia, C.; Chuang, S.; Cho, K.; Javey, A.; Wallace, R.M. Hole Contacts on Transition Metal Dichalcogenides: Interface Chemistry and Band Alignments. ACS Nano 2014, 8, 6265-6272. [CrossRef]

69. Freedy, K.; Zhang, H.; Bendersky, L.; Davydon, A.; McDonnell, S. Thermal Stability of Titanium Contacts to $\mathrm{MoS}_{2}$. ACS Appl. Mater. Interf. 2019, 11, 35389-35393. [CrossRef]

70. Domask, A.; Gurunathan, R.; Mohney, S. Transition Metal-MoS 2 Reactions: Review and Thermodynamic Predictions. J. Electron. Mater. 2015, 44, 4065-4079. [CrossRef]

71. Mcgovern, I.T.; Mcgilp, J.F.; Hughes, G.J.; Mckinley, A.; Williams, R.H.; Norman, D. Soft-X-Ray Photoemission Spectroscopy of Chemical-Reactivity at Metal-Gase Interfaces. Vacuum 1983, 33, 607-612. [CrossRef]

72. Brillson, L. Chemical reactions and local charge redistribution at metal-CdS and CdSe interfaces. Phys. Rev. B 1978, 18, 2431. [CrossRef]

73. Freedy, K.M.; Giri, A.; Foley, B.M.; Barone, M.R.; Hopkins, P.E.; McDonnell, S. Titanium Contacts to Graphene: Process-Induced Variability in Electronic and Thermal Transport. Nanotechnology 2017, 29, 145201. [CrossRef]

74. Kurtin, S.; McGill, T.; Mead, C. Fundamental transition in the electronic nature of solids. Phys. Rev. Lett. 1969, 22, 1433. [CrossRef]

75. Smyth, C.M.; Walsh, L.A.; Bolshakov, P.; Catalano, M.; Addou, R.; Wang, L.; Kim, J.; Kim, M.J.; Young, C.D.; Hinkle, C.L.; et al. Engineering the Palladium-WSe ${ }_{2}$ Interface Chemistry for Field Effect Transistors with High-Performance Hole Contacts. ACS Appl. Nano Mater. 2019, 2, 75-88. [CrossRef]

76. Park, W.; Kim, Y.; Sang Kyung, L.; Jung, U.; Jin Ho, Y.; Cho, C.; Yun Ji, K.; Sung Kwan, L.; In Seol, H.; Lee, H.; et al. Contact resistance reduction using Fermi level de-pinning layer for $\mathrm{MoS}_{2}$ FETs. In Proceedings of the 2014 IEEE International Electron Devices Meeting, 15-17 December 2014; pp. 5.1.1.-5.1.4.

77. Park, W.; Min, J.W.; Shaikh, S.F.; Hussain, M.M. Stable $\mathrm{MoS}_{2}$ Field-Effect Transistors Using $\mathrm{TiO}_{2}$ Interfacial Layer at Metal/MoS 2 Contact. Phys. Status Solid. A 2017, 214. [CrossRef]

78. Kim, G.-S.; Kim, S.-H.; Park, J.; Han, K.H.; Kim, J.; Yu, H.-Y. Schottky Barrier Height Engineering for Electrical Contacts of Multilayered $\mathrm{MoS}_{2}$ Transistors with Reduction of Metal-Induced Gap States. ACS Nano 2018, 12, 6292-6300. [CrossRef] [PubMed]

79. Kaushik, N.; Karmakar, D.; Nipane, A.; Karande, S.; Lodha, S. Interfacial n-Doping Using an Ultrathin $\mathrm{TiO}_{2}$ Layer for Contact Resistance Reduction in $\mathrm{MoS}_{2}$. ACS Appl. Mater. Interf. 2016, 8, 256-263. [CrossRef]

80. Freedy, K.M.; Olson, D.H.; Hopkins, P.E.; McDonnell, S.J. Titanium Contacts to $\mathrm{MoS}_{2}$ with Interfacial Oxide: Interface Chemistry and Thermal Transport. Phys. Rev. Mater. 2019, 3, 104001. [CrossRef]

81. Han, J.; Lee, J.; Lee, J.; Woo, H.; Kim, J.; Jo, Y.; Cho, S.; Kim, H.; Kim, H.; Pawar, S.M.; et al. Electrical properties of N2- and H2 -annealed bulk $\mathrm{MoS}_{2}$ /metal junctions. J. Korea Phys. Soc. 2015, 67, 1228-1231. [CrossRef]

82. Baugher, B.W.H.; Churchill, H.O.H.; Yang, Y.; Jarillo-Herrero, P. Intrinsic Electronic Transport Properties of High-Quality Monolayer and Bilayer $\mathrm{MoS}_{2}$. Nano Lett. 2013, 13, 4212-4216. [CrossRef] 
83. Liu, W.; Kang, J.; Sarkar, D.; Khatami, Y.; Jena, D.; Banerjee, K. Role of Metal Contacts in Designing High-Performance Monolayer n-Type WSe 2 Field Effect Transistors. Nano Lett. 2013, 13, 1983-1990. [CrossRef]

84. Freedy, K. Interface Studies of Metal/2D Material Contacts. Ph.D. Thesis, University of Virginia, Charlottesville, VA, USA, 2019. article distributed under the terms and conditions of the Creative Commons Attribution (CC BY) license (http://creativecommons.org/licenses/by/4.0/). 